\title{
A multiscale analytical approach to evaluate osseointegration
}

\author{
Anders Palmquist $\mathbb{B}^{1}$
}

Received: 15 December 2017 / Accepted: 18 April 2018 / Published online: 7 May 2018

(c) The Author(s) 2018

\begin{abstract}
Osseointegrated implants are frequently used in reconstructive surgery, both in the dental and orthopedic field, restoring physical function and improving the quality of life for the patients. The bone anchorage is typically evaluated at micrometer resolution, while bone tissue is a dynamic composite material composed of nanoscale collagen fibrils and apatite crystals, with defined hierarchical levels at different length scales. In order to understand the bone formation and the ultrastructure of the interfacial tissue, analytical strategies needs to be implemented enabling multiscale and multimodal analyses of the intact interface. This paper describes a sample preparation route for successive analyses allowing assessment of the different hierarchical levels of interest, going from macro to nano scale and could be implemented on single samples. Examples of resulting analyses of different techniques on one type of implant surface is given, with emphasis on correlating the length scale between the different techniques. The bone-implant interface shows an intimate contact between mineralized collagen bundles and the outermost surface of the oxide layer, while bone mineral is found in the nanoscale surface features creating a functionally graded interface. Osteocytes exhibit a direct contact with the implant surface via canaliculi that house their dendritic processes. Blood vessels are frequently found in close proximity to the implant surface either within the mineralized bone matrix or at regions of remodeling.
\end{abstract}

\section{Introduction}

The term osseointegration, meaning a direct structural connection between living bone and an implant surface, was coined by Professor P.I. Brånemark [1]. The pioneering development of the osseointegrated dental implant during the 60 and 70s [2] led to their global introduction in the 80s and is currently a routine treatment modality in dentistry. Since then, other clinical applications have emerged such as osseointegrated facial prostheses, bone anchored hearing aid, and major limb amputation prosthesis [3].

The healing around commercially pure titanium (cp-Ti) implants was originally described as being very similar to natural bone healing [4], hence being biocompatible and avoiding the formation of fibrous encapsulation.

Electronic supplementary material The online version of this article (https://doi.org/10.1007/s10856-018-6068-y) contains supplementary material, which is available to authorized users.

Anders Palmquist

anders.palmquist@biomaterials.gu.se

1 Department of Biomaterials, Sahlgrenska Academy at University of Gothenburg, Göteborg, Sweden
Transmission electron microscopy (TEM) was used extensively, and demonstrated intimate contact between bone and the implant surface, however, often separated by an electron lucent or electron dense layer in the range of $20-50 \mathrm{~nm}$, followed by mineralized collagenous bone, despite the frequent use of demineralization (summarized in [5]). An alternative theory, especially for roughened implant surfaces was the contact osteogenesis theory [6], where a $\mu \mathrm{m}$ thick cement line is formed at the immediate implant surface [7], similar to the cement line separating osteons of different ages, characterized as a collagen deficient hypermineralized zone [8].

Recently, it has been proposed that bone healing around implants is a "foreign body reaction in equilibrium" with a bony encapsulation, characterized as a poorly vascularized dense tissue interfacing the implant surface [9]. However, no experimental data has been shown to support this latter theory and standardized protocols for the evaluation of osseointegration at different length-scales and resolutions are needed in order to characterize the bone tissue interfacing an implant.

The aim of this article is to describe an analytical strategy to probe the different length-scales of osseointegration going from macro to nano. The focus is to have a platform enabling comprehensive, multiscale and multimodal 
analysis of single samples, allowing detailed characterization of clinical retrieved samples where the limited amount of material poses a major challenge. This review is limited to structural and compositional analyses and does not cover the cellular and molecular biology underlying osseointegration, which may be found elsewhere [10-14].

\section{Bone tissue}

Bone tissue, a highly hierarchical biocomposite material (Fig. 1) mainly composed of an organic matrix (collagen type I) and an inorganic reinforcement phase (apatite), is an adaptive tissue constantly undergoing remodeling.

Bone formation occurs through secretion of tropocollagen by the osteoblasts (bone forming cells) which is later mineralized. The early healing is characterized by the rapid formation of woven bone, an unorganized bone tissue which is later remodeled into more ordered bone through the coupled action of osteoclasts (bone resorbing cells) and osteoblasts. In this process, the osteoblasts start a coordinated action of bone formation and it is believed that they can orient the collagen matrix [15] leading to the higher hierarchical levels through a bottom-up approach. In the bone formation process, some osteoblasts stop producing extracellular matrix and instead start undergoing differentiation into osteocytes and become entrapped within the matrix produced by their neighboring osteoblasts. The osteocyte resides within lacunae (ellipsoidal shaped cavities in the bone) and the osteocyte is connected with the neighboring osteocytes, the blood circulation, and to the osteoblast (in a bone formation site) and lining cells (in a steady state) via the lacuno-canalicular network (LCN). It is believed that the osteocyte is the mechanosensing cell [16] responsible for adaptive remodeling of bone, hence maintenance of structural integrity and long-term performance.

The mechanics of bone (in the context of bone formation around metal implants, mechanical load-transfer from the metal into the surrounding bone, and adaptive remodeling etc.) are strongly dependent on the nanoscale organization and composition. It is therefore important to understand how bone forms on an implant surface, generally, and whether this nanoscale organization varies with respect to implant surface modification. Technical challenges in the preparation of TEM samples of the interfacial bone led to the development of strategies involving elimination of the bulk properties of the implant in the sample preparation. This was achieved either through the use of polymer implants with a thin coating of titanium (restricted to experimental studies) [17], mechanically separating the implant from the embedded bone tissue [18], or by electrochemically dissolving bulk titanium while the surface oxide layer was left intact [19]. All these techniques had their shortcomings and the focused ion beam (FIB) milling technique for the preparation of intact bone-metal interface samples for TEM was introduced in 2006 [20].

\section{Ex vivo tissue preservation and handling}

Tissue-implant samples are retrieved from the biological milieu, either from designed experimental models in animals or clinically retrieved from patients. The tissues undergo chemical fixation by immersion in aldehyde solutions, dehydration in a graded series of ethanol, and successive resin infiltrated prior to polymerization. This procedure was developed in order to be able to prepare undecalcified ground-sections for histology [21]. Fixation,

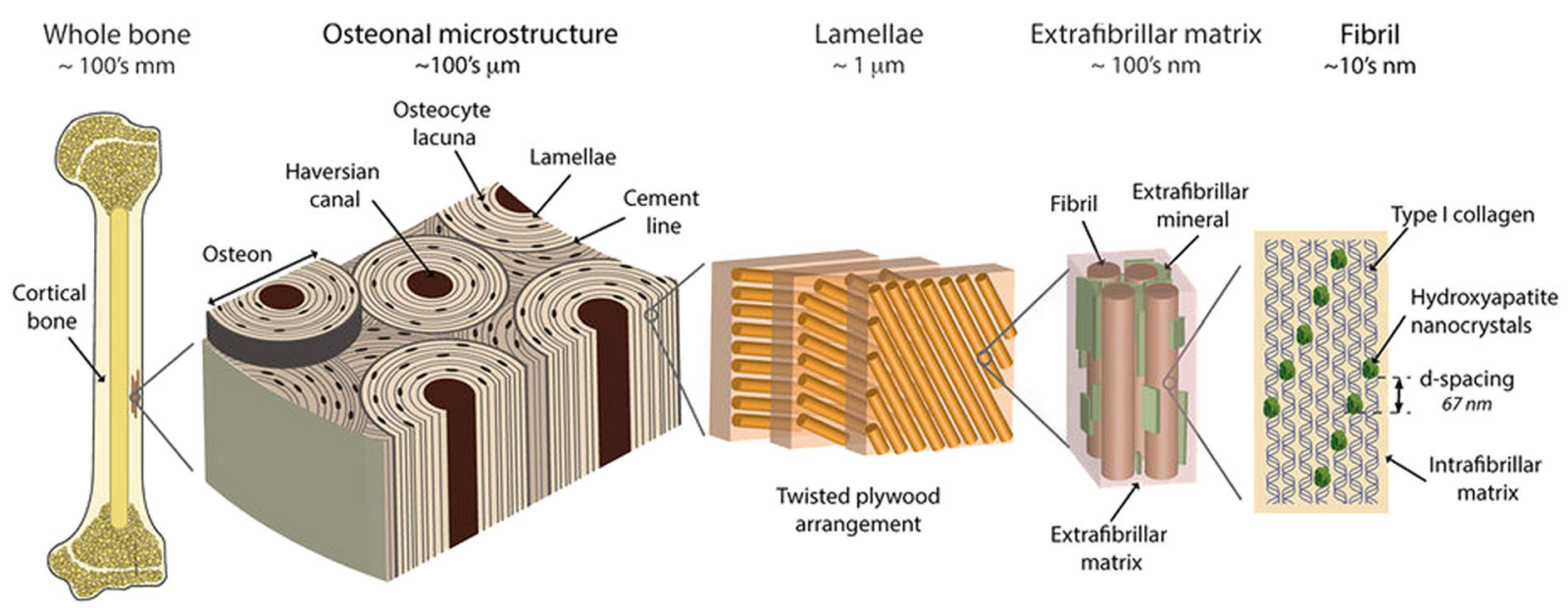

Fig. 1 Bone hierarchy: Illustration of the different hierarchical levels of bone tissue with corresponding length scales, from macro to nano scale. Reprinted with permission from Springer Nature [71] 


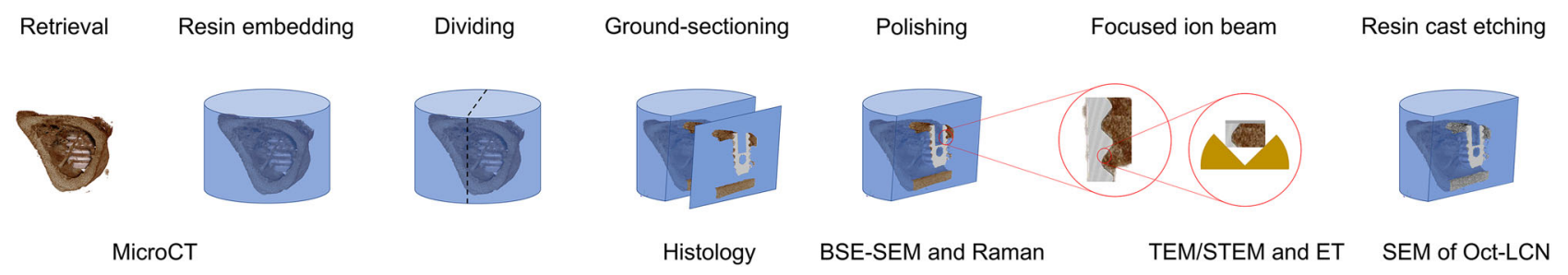

Fig. 2 Multiscale and multimodal analysis: The work-flow from retrieval and sample processing to sequential evaluation using a range of imaging and complementary spectroscopic techniques allowing comprehensive analysis of the same specimen
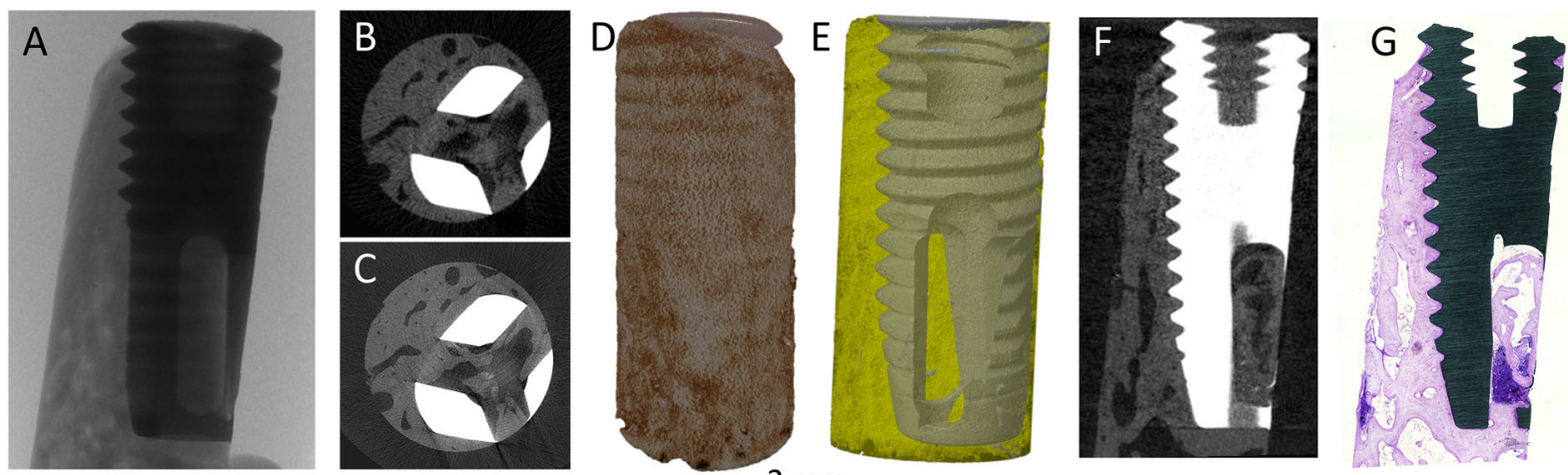

$2 \mathrm{~mm}$

Fig. 3 Macro level of osseointegration: Different views of a micro-CT analysis starting with a X-ray imaging. b Typical reconstruction of a low-resolution scan, $12 \mu \mathrm{m}$ voxel size (typically $15 \mathrm{~min}$ ). c Typical reconstruction of a high-resolution scan, $2.5 \mu \mathrm{m}$ voxel size (typically $8 \mathrm{~h}$ ). d A three-dimensional volume rendering of the reconstructed

dehydration, and resin embedding tend to induce dimensional changes and distort the ultrastructure [22, 23]. However, it is possible to perform high-resolution analyses in combination with histology [24], and therefore such sample preparation methods are suitable for a successive analytical strategy even for clinically retrieved implants where limited volume of biological tissue and/or number of samples are obtained. In Fig. 2, the sample preparation chain is shown to illustrate the correlative approach enabling multiscale and multimodal analysis of the intact bone-implant interface.

\section{Successive analytical approach and examples}

To exemplify the successive analytical approach, examples are shown of a hierarchically structured implant surface having a distinct microtopography and superimposed nanostructure (Supplementary Figure 1), from several experimental and clinical retrieval studies [24-30] in combination with the development of different analytical techniques adapted for the bone-implant interface [30-34]. image stack. e A three-dimensional surface rendering of the segmented data set representing the implant (grey) and bone (yellow) which has been made semi-transparent. f Data set rotated to locate the slice obtained as the histological ground-section. g Overview image of the ground-section stained by toluidine blue

\subsection{Micro-focused X-ray computed tomography (micro-CT)}

Micro-CT is the least destructive technique, where minimal sample preparation is needed and is emerging in the field of osseointegration to study the bone-implant interface. The technique offers a rapid data acquisition, generating results without the need for tedious sample preparation that is generally necessary for histology. This means that samples can be scanned at any stage from the time of retrieval to post-embedment. The biggest advantage of micro-CT over histomorphometry is that morphometric measurements can be performed in 3D rather than having one representative histological section from each sample. Furthermore, microCT imaging can be directly correlated to histology by locating the histological section in the micro-CT data set (Fig. 3).

Nevertheless, the technique is associated with artifacts introduced during data acquisition, many of which may be corrected for during reconstruction. However, widely differing densities of the metal implant and the biological tissue compromise the analysis close to the implant surface $[35,36]$. The technique has been validated to assess bone volume accurately by correlating with histological 
measurements $[37,38]$ even at fast/low resolution scans (e.g., $14 \mu \mathrm{m})$. While some investigators have reported a correlation between micro-CT and BSE-SEM based measurements of bone-implant contact [39], it is advisable that measurements be correlated with histology and histomorphometry.

\subsection{Light optical microscopy (LM)}

The gold standard in biomaterials research is to evaluate tissue response to biomaterials using simple optical microscopy, where both quantitative histomorphometry and qualitative histology can be performed. Qualitative histology enables a detailed description of the state of the tissues, the maturity (woven, lamellar, or osteonal) and the presence of cells such as different bone cells (osteoblasts, osteoclasts and osteocytes), adipose cells, blood cells, inflammatory cells and multinucleated giant cells as well as the general morphology and to some extent the structure and alignment of the tissues. A limiting factor is the sample preparation, where a section of single-cell thickness is preferable. Moreover, the fixation and dehydration steps must be optimized in order to avoid large artifacts from shrinkage especially in unmineralized areas, i.e., the marrow compartment. It has been shown that quantification of boneimplant contact is highly dependent on the sectioning direction as well as the thickness of the ground-section $[40,41]$.

The morphology of the tissue in association with the implant surface, bone lamellar orientation and alignment of osteocyte lacunae as well as the presence of osteocytes in the lacunae could be evaluated (Fig. 3). Bone remodeling is frequently observed both close to and at a distance from the implant surface where osteoblasts are often co-localized with osteoclasts as well as blood supply. The mineralization front (and therefore the direction of bone formation) and the embedment of differentiating osteocytes can be observed (Supplementary Figure 2) (Figs. 4 and 5).

\subsection{Raman spectroscopy}

Raman spectroscopy is becoming increasingly used in the field of biomaterials, as a versatile tool requiring minimal sample preparation and is quick and minimally destructive. It has been used for material characterization [42], evaluation of in vitro formed extracellular matrix [43] as well as the molecular composition of bone tissue before [44] and after resin embedding [45] and is considered to give an assessment of the bone quality [46]. Site-specific analyses of interfaces such as natural bone interfaces, i.e., cement lines [47] or the bone-implant interface can be carried out [48, 49]. Confocal Raman imaging allows 2D and 3D mapping of composition at submicron resolution, and such data can be easily correlated with other imaging techniques. In composites such as bone, the relative amounts of the individual organic and inorganic constituents can be determined. Raman spectroscopy is particularly useful in identification of different calcium phosphate phases found in bone [50]. Furthermore, in experiments involving selective removal of tissue components for structural analysis,
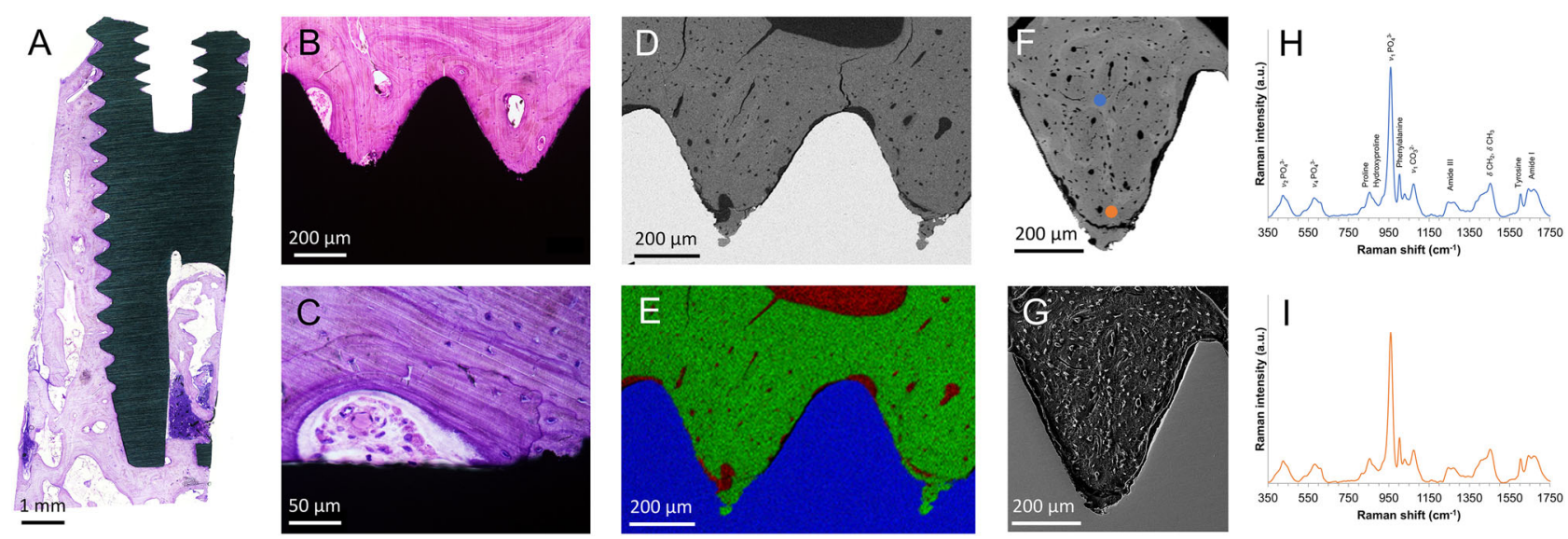

Fig. 4 Microscale osseointegration: Light optical microscopy combined with BSE-SEM, EDS, Raman spectroscopy and SE-SEM of resin cast etched samples, showing the successive increase in magnification to follow the bone growth adjacent to the implant. a Overview histological image, showing the amount of bone tissue around the implant. b Closer view of two threads almost completely filled with mature bone tissue. c A closer view at the implant surface showing a remodeling zone with active bone formation, blood supply. Osteocytes are visible in the bone with stained nuclei. d BSE-SEM image of two threads showing a similar picture as the histology, mature bone filling the threads. e Correlative elemental mapping of the two threads, showing calcium (green), titanium (blue) and carbon (red). f Single thread in BSE-SEM showing a biomechanical testing induced fractured zone at the thread valley as well as osteocytes and blood vessels throughout the tissue. g Corresponding thread after resin cast etching, showing the plastic surrounding osteocytes and blood vessels protruding from the etched bone surface. $\mathbf{h}$ and $\mathbf{i}$ Raman spectra from the corresponding spots marked in $\mathbf{f}$, showing the molecular composition of the tissue. Images modified and reprinted with permission from John Wiley \& Sons and Public Library of Science [25, 27] 

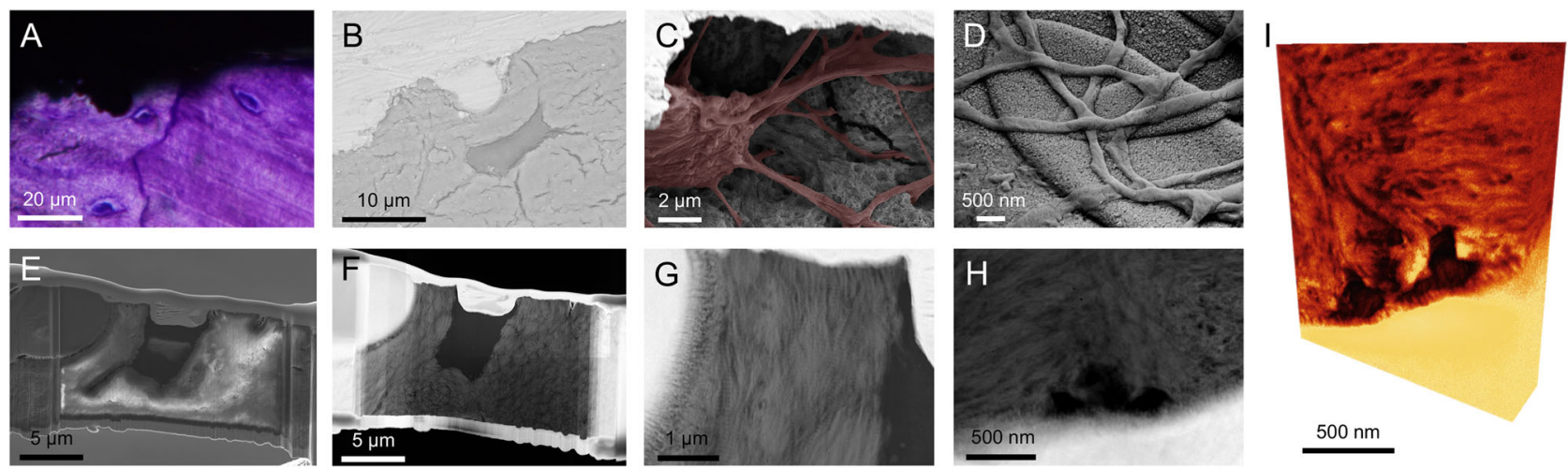

Fig. 5 Osteocytes at the implant surface: The osteocyte connection to the implant surface. a Histological image of osteocytes close to the implant surface, the cell nuclei stained in blue. b BSE-SEM image of an osteocyte close to the implant surface. c Osteocyte close to the implant surface shown after resin cast etching where the canaliculi can be observed reaching the implant surface (Osteocyte and canaliculi highlighted in red). d Canaliculi making intimate contact with the implant surface, a top view showing the network of canaliculi. e FIB section during TEM sample preparation made across the osteocyte in b. A canaliculi is seen running in the 8 o'clock direction. f STEM image of the thin sample, the canaliculi was removed during the thinning process. $\mathrm{g}$ Closer view of the bone between the osteocyte

Raman spectroscopy can be used to identify and characterize the remaining component [51].

\subsection{Scanning electron microscopy (SEM)}

SEM is a versatile and easy to use technique that enables high-resolution imaging in conjunction with chemical analyses. Different contrast phenomena can be used to highlight different aspects. The most frequently used are secondary electron (SE-SEM) and backscattered electron (BSE-SEM) modes, where the former gives contrast from the surface texture and the latter gives a $Z$-(atomic number) contrast. The $Z$-contrast is particularly useful for studying bone, since the degree of mineralization is directly resolved and could be calibrated using standard materials to determine the absolute wt. \% calcium content [52]. In many ways, BSE-SEM provides a similar picture of the mineralized tissue as histology, where the morphology of the tissue, degree of mineralization and alignment of osteocytes could be directly visualized, in addition to details in remodeling zones with embedment of osteocytes and the granular appearance of the mineralization front (Supplementary Figure 2). Electron bombardment onto the sample surface induces charging artifacts, which are typically circumvented by the addition of a thin conductive coating. Another solution is the use of an environmental SEM operated at low vacuum with the presence of water vapor to minimize (or completely eliminate) the charging artifacts, without the need of an electrically conductive coating. lacuna and the implant surface showing a uniform directionality, indicating that the former osteoblast, now osteocyte produced the bone in a contact osteogenesis fashion. Collagen banding is observed perpendicular to the implant surface as well as the lacuna indicating collagen parallel to the surface, the morphology further indicate a mature bone with fibril bundles of $1-2 \mu \mathrm{m}$ in diameter. $\mathbf{h}$ STEM image of canaliculi directly interfacing the implant surface. $\mathbf{i}$ Corresponding electron tomography volume rendering of $\mathbf{h}$ (Courtesy of Assistant Professor Kathryn Grandfield). Images reprinted and modified with permission from the American Chemical Society and Public Library of Science [27, 33]

Secondary electron imaging generates contrast from surface irregularities and is hence used for evaluating osteocyte lacunae and the canaliculi network after resin cast etching [33] where the resin filled voids in bone could be highlighted, showing the intimate contact between the canalicular network and the implant surface as well as the interconnectivity of the LCN with the blood vessels and bone marrow [53].

In a successive manner, BSE-SEM is performed on polished surfaces without the use of a conductive coating. The sample is subsequently processed for resin cast etching, coated with a conductive coating for high vacuum SE-SEM, to be able to evaluate the same region of interest.

\subsection{Focused ion beam-scanning electron microscopy (FIB-SEM)}

FIB-SEM is a useful tool in biomaterials research, where both 3D reconstructions could be performed using a serial slice-and-view (SSV) function. Much work has been done to study the ultrastructure of lamellar bone where imaging was performed through successive lamellae and reconstructing the lacuno-canalicular network, using a decalcification and staining protocol in order to visualize the collagen mesh [54] Without decalcification, the methodology has been used to visualize bone ingrowth in microporous titanium oxide, however without being able to resolve the unique ultrastructural characteristics of bone [55]. 
Another application of FIB-SEM is preparation of TEM samples. Thin lamellae or needle-shaped samples are cut out with sub-micrometer precision, readily cutting through both metal and undecalcified bone. The dimensions of the resulting sample are limited, and typically in the $25 \times 1 \mu \mathrm{m}$ range, while being able to obtain a thickness of roughly $100 \mathrm{~nm}$. For more information on TEM sample preparation, the interested reader is referred elsewhere [56, 57].

\subsection{Transmission electron microscopy (TEM)}

The TEM is a very powerful instrument with not only high magnifying power but also multiple in-built analytical techniques, such as diffraction, energy dispersive X-ray spectroscopy (EDS), and electron energy loss spectroscopy (EELS). For bone-implant interface analysis, during the 80 and 90s, the TEM was used mainly for imaging but no analytical techniques were implemented. The first chemical mapping was reported in 2006 [20] and much work has been done since. Furthermore, the use of scanning transmission electron microscopy (STEM) and the use of a nanoprobe allow elemental analysis with high spatial resolution as compared to the SEM where typically $\mu \mathrm{m}$ resolution is obtained. The contrast phenomena typically used are either bright-field TEM or high-angle annular dark field (HAADF-) STEM, where the latter gives $Z$-contrast and is preferred for the bone-implant interface.

The bone-implant interface has been shown to be composed of bundles of collagen fibrils running parallel to the implant surface in very close proximity to the oxide layer. In the case of nanostructured implant surfaces, apatite ingrowth into surface irregularities has been shown both by EDS [25, 28] and EELS [30, 33, 34]. The presence of features smaller than the thickness of the sample pose considerable difficulties in resolving the actual interface due an overlap in information, necessitating the use of highresolution 3D imaging techniques.

For the osteocyte lacuno-canalicular network, as the sample is sectioned from only a top view, it is difficult to selectively have canaliculi in the sample, but due to their large presence in the bone, often transversely cut circular features (typically $200 \mathrm{~nm}$, in agreement with canaliculi [23]) are visible in the TEM section, while part of osteocytes could be sectioned readily [33].

The structure and alignment of the tissue components, for example the size and orientation of apatite crystallites, can be evaluated, thus revealing details of the smallest hierarchical level of mineralized tissue in osseointegration [28]. The ultrastructural pattern of bone is highly dependent on the cutting direction, where mineralized collagen fibers may be cut longitudinally or transversally. In longitudinal sectioning, characteristic $67-\mathrm{nm}$ striations are seen while holes and circular patterns are observed in transversal sectioning.

\subsection{Electron tomography (ET)}

Electron tomography uses similar principle as micro-CT, where a rotation series of images is acquired, aligned, and reconstructed by back-projection. When performed in HAADF-STEM, similar contrast is obtained as in micro$\mathrm{CT}$ and difficulties in reconstruction due to diffraction contrast as in regular TEM can be avoided. It has successfully been performed on the bone-implant interface enabling a greater understanding of apatite ingrowth into the nanostructured surface oxide layer [26, 30, 31, 33], however, limitations in the reconstruction due to lack of images originating from limited tilt angles creates artifacts in the images. The use of needle-shaped samples and special sample holders enables complete rotation and improved 3D reconstruction [34]. As image acquisition is performed with high Z-contrast, contrast based segmentation protocols similar to micro-CT can be applied, thus permitting quantification and enhanced visualization of collagen structure and orientation. Furthermore, with the use of needle-shaped sample, electron tomography could may be complemented by EELS tomography (chemical 3D mapping with nanometer resolution) and atom probe tomography (APT).

\subsection{Complementary analytical techniques}

Additional complementary tools may be utilized at different stages of the sequential analytical approach and will further bridge the different length scales and bring new dimensions to the analysis.

Synchrotron radiation at large scale facilities is of high interest, where multiple different analyses could be carried out, using different sample sizes obtaining various fields of view and spatial resolution levels. Particularly for tomographic techniques, higher flux enables improved resolution and contrast than conventional methods [58]. Phase contrast tomography can be used for improved resolution and complement lab-based micro-CT, where improved resolution at the implant interface could be obtained, as well as observing and distinguish low contrast components in the bone tissue in 3D [59]. The average alignment of the mineralized collagen bundles and crystal thickness could be obtained in 2D [60, 61] and 3D [62] by scanning small-angle X-ray scattering (sSAXS) tomography at comparable low resolution with larger field of view. At higher resolution, the direction of individual collagen bundles can be investigated [63, 64] however in smaller sample volumes of a few hundreds of micrometers. 2D sSAXS has been applied to characterize bone healing around degradable metal implants $[65,66]$. By ptychographic tomography, the osteocyte canaliculi network could be resolved in very small samples in the 


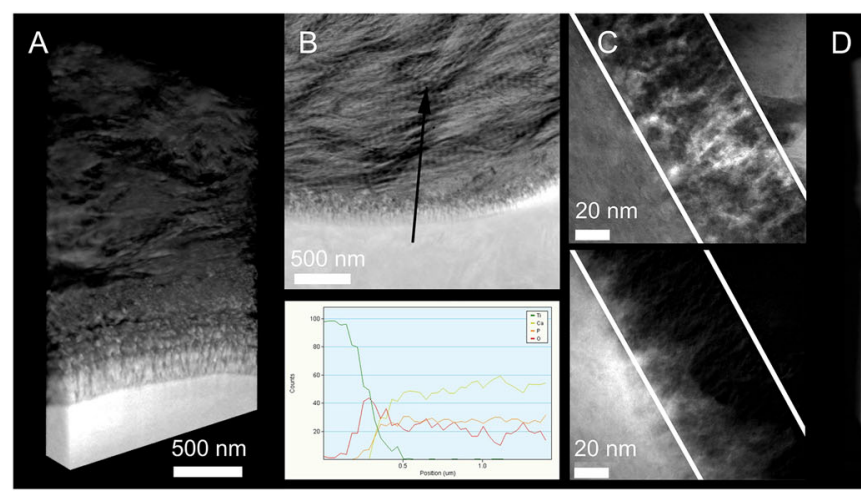

Fig. 6 Nano-osseointegration: The nano-scale characteristics of the bone-implant interface could be visualized and analyzed using the transmission electron microscope. a A $3 \mathrm{D}$ rendering of the bone implant interface where the collagen bundles are observed parallel to the implant surface running in the plane of the section, collagen banding is observed perpendicular to the implant surface. The individual mineralized collagen fibrils which bundles up to make the bundles could be observed in the tomogram very close to the outermost surface of the oxide layer. b STEM image of the interface showing the typical collagen banding and parallel fashion of the collagen to the implant surface. Site specific chemical analysis by EDS across the interface show a zone of overlapping information indicating apatite formation in the nanostructures formed by the surface oxide. $\mathbf{c}$ TEM image of the interface with corresponding EFTEM image filtered for the calcium showing the ingrowth into the nanostructures. d A

range of tens of micrometers [67]. It is possible to apply most of these techniques to plastic embedded samples at successive stages depending on their need for smaller samples sizes, and could hence be integrated in the proposed analytical approach. Following STEM tomography of needle-shaped samples preparing using the FIB (Fig. 6) [34], the tip can be thinned down further for EELS tomography and APT. APT is also becoming popular in the field of biomaterials [68] and bone research [69], where atomic resolution can be obtained in 3D. For further reading on high-resolution techniques, the interested reader is referred elsewhere [70].

\section{Concluding remarks}

Through the use of correlative and complementary imaging and analytical techniques, osseointegration can be probed and evaluated at relevant hierarchical scales. The boneimplant interface shows an intimate contact between mineralized collagen bundles and the outermost surface of the oxide layer, while within the nanoscale surface features only bone mineral is found, thus creating a functionally graded interface. Osteocytes exhibit a direct contact with the implant surface via canaliculi that house their dendritic processes. Blood vessels are frequently found in close proximity to the implant surface either within the mineralized bone matrix or at regions of remodeling. series of images of electron tomography of a needle-shaped implant where full rotation could be performed for improved reconstruction. In the perpendicular slices the bone structure with darker features (carbon rich collagen fibrils) and aligned apatite could be visualized while at the interface to the implant surface, the structure of the oxide layer with nanoscale features could be seen filled with apatite. Two 3D surface rendering of contrast-based segmented data set with implant (grey), collagen fibrils (red) and with/without apatite (yellow), showing the individual collagen fibrils seemingly being from two different collagen bundles (bundles typically in the range of $1-2 \mu \mathrm{m}$ in diameter) with slightly different alignment, both however in a rather parallel to the implant surface. Images reprinted and modified with permission from the Royal Society (UK), the American Chemical Society and the Royal Society of Chemistry [26, 30, 33, 34]

Acknowledgements The author would like to thank Dr. Furqan Ali Shah and Professor Peter Thomsen at the University of Gothenburg and Assistant Professor Kathryn Grandfield at McMaster University for all the fruitful scientific discussions during the years. Ms Lena Emanuelsson, laboratory technician at the University of Gothenburg for her enormous expertise and long-term experience in sample preservation and preparation. Financial support was received from the BIOMATCELL VINN Excellence Center of Biomaterials and Cell Therapy, the Region Västra Götaland, an ALF/LUA grant, the IngaBritt and Arne Lundberg Foundation, Swedish Research Council, the Dr. Felix Neubergh Foundation, Promobilia, the Hjalmar Svensson Foundation, and the Materials Science Area of Advance at Chalmers and the Department of Biomaterials, University of Gothenburg.

\section{Compliance with ethical standards}

Conflict of interest The authors declare that they have no conflict of interest.

Open Access This article is distributed under the terms of the Creative Commons Attribution 4.0 International License (http://crea tivecommons.org/licenses/by/4.0/), which permits unrestricted use, distribution, and reproduction in any medium, provided you give appropriate credit to the original author(s) and the source, provide a link to the Creative Commons license, and indicate if changes were made.

\section{References}

1. Brånemark PI, Hansson BO, Adell R, Breine U, Lindström J, Hallen $\mathrm{O}$, et al. Osseointegrated implants in the treatment of the edentulous jaw. Experience from a 10-year period. Scand J Plast Reconstr Surg Suppl. 1977;16:1-132. 
2. Branemark PI, Adell R, Breine U, Hansson BO, Lindstrom J, Ohlsson A. Intra-osseous anchorage of dental prostheses. I. Experimental studies. Scand J Plast Reconstr Surg. 1969;3:81-100.

3. Brånemark R, Brånemark PI, Rydevik B, Myers RR. Osseointegration in skeletal reconstruction and rehabilitation: a review. $\mathrm{J}$ Rehabil Res Dev. 2001;38:175-81.

4. Albrektsson T, Albrektsson B. Osseointegration of bone implants. A review of an alternative mode of fixation. Acta Orthop Scand. 1987;58:567-77.

5. Palmquist A. On a novel technique for preparation and analysis of the implant surface and its interface to bone. Göteborg, Sweden: Department of Biomaterials, Institute of Clinical Sciences, Sahlgrenska Academy at University of Gothenburg; 2008.

6. Davies JE. Bone bonding at natural and biomaterial surfaces. Biomaterials. 2007;28:5058-67.doi:S0142-9612(07)00585-6 [pii] 10.1016/j.biomaterials.2007.07.049.

7. Davies JE, Mendes VC, Ko JC, Ajami E. Topographic scale-range synergy at the functional bone/implant interface. Biomaterials. 2014;35:25-35. https://doi.org/10.1016/j.biomaterials.2013.09.072

8. Skedros JG, Holmes JL, Vajda EG, Bloebaum RD. Cement lines of secondary osteons in human bone are not mineral-deficient: new data in a historical perspective. Anat Rec A Discov Mol Cell Evol Biol. 2005;286:781-803. https://doi.org/10.1002/ar.a.20214

9. Albrektsson T, Dahlin C, Jemt T, Sennerby L, Turri A, Wennerberg A. Is marginal bone loss around oral implants the result of a provoked foreign body reaction? Clin Implant Dent Relat Res. 2014;16:155-65. https://doi.org/10.1111/cid.12142

10. Lennerås M, Palmquist A, Norlindh B, Emanuelsson L, Thomsen $\mathrm{P}$, Omar O. Oxidized titanium implants enhance osseointegration via mechanisms involving RANK/RANKL/OPG regulation. Clin Implant Dent Relat Res. 2015;17:e486-500. https://doi.org/10. 1111/cid.12276

11. Omar O, Lenneras M, Svensson S, Suska F, Emanuelsson L, Hall $\mathrm{J}$, et al. Integrin and chemokine receptor gene expression in implant-adherent cells during early osseointegration. J Mater Sci Mater Med. 2010;21:969-80. https://doi.org/10.1007/s10856-0093915-x

12. Omar O, Svensson S, Zoric N, Lenneras M, Suska F, Wigren S, et al. In vivo gene expression in response to anodically oxidized versus machined titanium implants. J Biomed Mater Res A. 2010;92:1552-66. https://doi.org/10.1002/jbm.a.32475

13. Omar OM, Lenneras ME, Suska F, Emanuelsson L, Hall JM, Palmquist A, et al. The correlation between gene expression of proinflammatory markers and bone formation during osseointegration with titanium implants. Biomaterials. 2011;32:374-86. doi: S0142-9612(10)01163-4 [pii] 10.1016/j.biomaterials.2010.09.011

14. Palmquist A, Omar OM, Esposito M, Lausmaa J, Thomsen P. Titanium oral implants: surface characteristics, interface biology and clinical outcome. J R Soc Interface. 2010;7:S515-27. https:// doi.org/10.1098/rsif.2010.0118.focus

15. Yamamoto T, Hasegawa T, Sasaki M, Hongo H, Tabata C, Liu Z, et al. Structure and formation of the twisted plywood pattern of collagen fibrils in rat lamellar bone. $\mathrm{J}$ Electron Microsc. 2012;61:113-21. https://doi.org/10.1093/jmicro/dfs033

16. Klein-Nulend J, Bakker AD, Bacabac RG, Vatsa A, Weinbaum S. Mechanosensation and transduction in osteocytes. Bone. 2013;54:182-90. https://doi.org/10.1016/j.bone.2012.10.013

17. Albrektsson T, Hansson HA, Ivarsson B. Interface analysis of titanium and zirconium bone implants. Biomaterials. 1985;6:97-101. doi:0142-9612(85)90070-5 [pii]

18. Thomsen P, Ericson LE. Light and transmission electron microscopy used to study the tissue morphology close to implants. Biomaterials. 1985;6:421-4.

19. Sennerby L, Ericson LE, Thomsen P, Lekholm U, Astrand P. Structure of the bone-titanium interface in retrieved clinical oral implants. Clin Oral Implants Res. 1991;2:103-11.
20. Engqvist H, Botton GA, Couillard M, Mohammadi S, Malmstrom J, Emanuelsson L, et al. A novel tool for high-resolution transmission electron microscopy of intact interfaces between bone and metallic implants. J Biomed Mater Res A. 2006;78:20-4.

21. Donath K, Breuner G. A method for the study of undecalcified bones and teeth with attached soft tissues. The Sage-Schliff (sawing and grinding) technique. J Oral Pathol. 1982;11:318-26.

22. Palmquist A, Lindberg F, Emanuelsson L, Branemark R, Engqvist $\mathrm{H}$, Thomsen P. Morphological studies on machined implants of commercially pure titanium and titanium alloy (Ti6Al4V) in the rabbit. J Biomed Mater Res B Appl Biomater. 2009;91B:309-19. https://doi.org/10.1002/jbm.b.31404

23. Shah FA, Johansson BR, Thomsen P, Palmquist A. Ultrastructural evaluation of shrinkage artefacts induced by fixatives and embedding resins on osteocyte processes and pericellular space dimensions. J Biomed Mater Res A. 2015;103:1565-76. https:// doi.org/10.1002/jbm.a.35287

24. Palmquist A, Lindberg F, Emanuelsson L, Branemark R, Engqvist $\mathrm{H}$, Thomsen P. Biomechanical, histological, and ultrastructural analyses of laser micro and nano-structured titanium alloy implants: a study in rabbit. J Biomed Mater Res A. 2010;92 (4:1476-86. https://doi.org/10.1002/jbm.a.32439.

25. Palmquist A, Emanuelsson L, Branemark R, Thomsen P. Biomechanical, histological and ultrastructural analyses of laser micro and nano-structured titanium implant after 6 months in rabbit. $\mathrm{J}$ Biomed Mater Res B Appl Biomater. 2011;97(2:289-98. https:// doi.org/10.1002/jbm.b.31814.

26. Palmquist A, Grandfield K, Norlindh B, Mattsson T, Branemark $\mathrm{R}$, Thomsen $\mathrm{P}$. Bone-titanium oxide interface in humans revealed by transmission electron microscopy and electron tomography. J R Soc Interface. 2012;9:396-400. https://doi.org/10.1098/rsif. 2011.0420

27. Shah FA, Johansson ML, Omar O, Simonsson H, Palmquist A, Thomsen P. Laser-modified surface enhances osseointegration and biomechanical anchorage of commercially pure titanium implants for bone-anchored hearing systems. PLoS ONE. 2016;11: e0157504 https://doi.org/10.1371/journal.pone.0157504

28. Shah FA, Nilson B, Branemark R, Thomsen P, Palmquist A. The bone-implant interface-nanoscale analysis of clinically retrieved dental implants. Nanomedicine. 2014;10:1729-37. https://doi.org/ 10.1016/j.nano.2014.05.015

29. Branemark R, Emanuelsson L, Palmquist A, Thomsen P. Bone response to laser-induced micro and nano-size titanium surface features. Nanomedicine. 2011;7:220-7. doi:S1549-9634(10) 00357-6 [pii] 10.1016/j.nano.2010.10.006

30. Grandfield K, Gustafsson S, Palmquist A. Where bone meets implant: the characterization of nano-osseointegration. Nanoscale. 2013;5:4302-8. https://doi.org/10.1039/c3nr00826f

31. Grandfield K, Palmquist A, Engqyist H. Three-dimensional structure of laser-modified Ti6A14V and bone interface revealed with STEM tomography. Ultramicroscopy. 2013;127:48-52.

32. Palmquist A, Emanuelsson L, Sjovall P. Chemical and structural analysis of the bone-implant interface by TOF-SIMS, SEM, FIB and TEM: experimental study in animal. Appl Surf Sci. 2012;258:6485-94. https://doi.org/10.1016/J.Apsusc.2012.03.065

33. Shah FA, Wang X, Thomsen P, Grandfield K, Palmquist A. Highresolution visualization of the osteocyte lacuno-canalicular network juxtaposed to the surface of nanotextured titanium implants in human. Acs Biomater Sci Eng. 2015;1:305-13. https://doi.org/ 10.1021/ab500127y

34. Wang X, Shah FA, Palmquist A, Grandfield K. 3D characterization of human nano-osseointegration by on-axis electron tomography without the missing wedge. Acs Biomater Sci Eng. 2017;3:49-55.

35. Li JY, Pow EH, Zheng LW, Ma L, Kwong DL, Cheung LK. Quantitative analysis of titanium-induced artifacts and correlated 
factors during micro-CT scanning. Clin Oral Implants Res. 2014;25:506-10. https://doi.org/10.1111/clr.12200

36. Liu S, Broucek J, Virdi AS, Sumner DR. Limitations of using micro-computed tomography to predict bone-implant contact and mechanical fixation. J Microsc. 2012;245:34-42. https://doi.org/ 10.1111/j.1365-2818.2011.03541.x

37. Palmquist A, Shah FA, Emanuelsson L, Omar O, Suska F. A technique for evaluating bone ingrowth into $3 \mathrm{D}$ printed, porous Ti6Al4V implants accurately using X-ray micro-computed tomography and histomorphometry. Micron. 2017;94:1-8. https:// doi.org/10.1016/j.micron.2016.11.009

38. Stoppie N, van der Waerden JP, Jansen JA, Duyck J, Wevers M, Naert IE. Validation of microfocus computed tomography in the evaluation of bone implant specimens. Clin Implant Dent Relat Res. 2005;7:87-94.

39. Meagher MJ, Parwani RN, Virdi AS, Sumner DR. Optimizing a micro-computed tomography-based surrogate measurement of bone-implant contact. J Orthop Res. 2017. https://doi.org/10.1002/ jor. 23716

40. Johansson CB, Morberg P. Importance of ground section thickness for reliable histomorphometrical results. Biomaterials. 1995;16:91-5. doi:0142-9612(95)98268-J [pii]

41. Johansson CB, Morberg P. Cutting directions of bone with biomaterials in situ does influence the outcome of histomorphometrical quantifications. Biomaterials. 1995;16:1037-9. doi:0142961295949136 [pii]

42. Lopez-Heredia MA, Sohier J, Gaillard C, Quillard S, Dorget M, Layrolle P. Rapid prototyped porous titanium coated with calcium phosphate as a scaffold for bone tissue engineering. Biomaterials. 2008;29:2608-15. https://doi.org/10.1016/j.biomaterials.2008.02. 021

43. Gentleman E, Swain RJ, Evans ND, Boonrungsiman S, Jell G, Ball MD, et al. Comparative materials differences revealed in engineered bone as a function of cell-specific differentiation. Nat Mater. 2009;8:763-70. https://doi.org/10.1038/nmat2505

44. Penel G, Delfosse C, Descamps M, Leroy G. Composition of bone and apatitic biomaterials as revealed by intravital Raman microspectroscopy. Bone. 2005;36:893-901. https://doi.org/10.1016/j. bone.2005.02.012

45. Kazanci M, Wagner HD, Manjubala NI, Gupta HS, Paschalis E, Roschger $\mathrm{P}$, et al. Raman imaging of two orthogonal planes within cortical bone. Bone. 2007;41:456-61. https://doi.org/10.1016/j. bone.2007.04.200

46. Morris MD, Mandair GS. Raman assessment of bone quality. Clin Orthop Relat Res. 2011;469:2160-9. https://doi.org/10.1007/ s11999-010-1692-y

47. Milovanovic P, Vom Scheidt A, Mletzko K, Sarau G, Puschel K, Djuric $\mathrm{M}$, et al. Bone tissue aging affects mineralization of cement lines. Bone. 2018;110:187-93. https://doi.org/10.1016/j.bone. 2018.02.004

48. Shah FA, Omar O, Suska F, Snis A, Matic A, Emanuelsson L, et al. Long-term osseointegration of $3 \mathrm{D}$ printed $\mathrm{CoCr}$ constructs with an interconnected open-pore architecture prepared by electron beam melting. Acta Biomater. 2016;36:296-309. https://doi. org/10.1016/j.actbio.2016.03.033

49. Hoerth RM, Katunar MR, Gomez Sanchez A, Orellano JC, Cere SM, Wagermaier W, et al. A comparative study of zirconium and titanium implants in rat: osseointegration and bone material quality. J Mater Sci Mater Med. 2014;25:411-22. https://doi.org/ 10.1007/s10856-013-5074-3

50. Shah FA, Lee BEJ, Tedesco J, Larsson Wexell C, Persson C, Thomsen $\mathrm{P}$, et al. Micrometer-sized magnesium whitlockite crystals in micropetrosis of bisphosphonate-exposed human alveolar bone. Nano Lett. 2017;17:6210-6. https://doi.org/10. 1021/acs.nanolett.7b02888
51. Shah FA, Zanghellini E, Matic A, Thomsen P, Palmquist A. The orientation of nanoscale apatite platelets in relation to osteoblasticosteocyte lacunae on trabecular bone surface. Calcif Tissue Int. 2016;98:193-205. https://doi.org/10.1007/s00223-015-0072-8

52. Roschger P, Fratzl P, Eschberger J, Klaushofer K. Validation of quantitative backscattered electron imaging for the measurement of mineral density distribution in human bone biopsies. Bone. 1998;23:319-26.

53. Shah FA, Stenlund P, Martinelli A, Thomsen P, Palmquist A. Direct communication between osteocytes and acid-etched titanium implants with a sub-micron topography. J Mater Sci Mater Med. 2016;27:167 https://doi.org/10.1007/s10856-016-5779-1

54. Reznikov N, Almany-Magal R, Shahar R, Weiner S. Threedimensional imaging of collagen fibril organization in rat circumferential lamellar bone using a dual beam electron microscope reveals ordered and disordered sub-lamellar structures. Bone. 2013;52:676-83. https://doi.org/10.1016/j.bone.2012.10.034

55. Giannuzzi LA, Phifer D, Giannuzzi NJ, Capuano MJ. Twodimensional and 3-dimensional analysis of bone/dental implant interfaces with the use of focused ion beam and electron microscopy. J Oral Maxillofac Surg. 2007;65:737-47.

56. Giannuzzi LA, Kempshall BW, Schwarz SM, Lomness JK, Prenitzer BI, Stevie FA. FIB lift-out specimen preparation techniques: ex-situ and in-situ methods. In: Giannuzzi LA, Stevie FA, editors. Introduction to focused ion beams: instrumentation, theory, techniques and practice. Boston: Springer; 2005.

57. Jarmar T, Palmquist A, Branemark R, Hermansson L, Engqvist H, Thomsen P. Technique for preparation and characterization in cross-section of oral titanium implant surfaces using focused ion beam and transmission electron microscopy. J Biomed Mater Res A. 2008;87A:1003-9. https://doi.org/10.1002/jbm.a.31856

58. Sarve H, Lindblad J, Borgefors G, Johansson CB. Extracting 3D information on bone remodeling in the proximity of titanium implants in SRmuCT image volumes. Comput Methods Prog Biomed. 2011;102:25-34. https://doi.org/10.1016/j.cmpb.2010. 12.011

59. Giuliani A, Mazzoni S, Mele L, Liccardo D, Tromba G, Langer M. Synchrotron phase tomography: an emerging imaging method for microvessel detection in engineered bone of craniofacial districts. Front Physiol. 2017;8:769 https://doi.org/10.3389/fphys. 2017.00769

60. Rinnerthaler S, Roschger P, Jakob HF, Nader A, Klaushofer K, Fratzl P. Scanning small angle X-ray scattering analysis of human bone sections. Calcif Tissue Int. 1999;64:422-9.

61. Turunen MJ, Kaspersen JD, Olsson U, Guizar-Sicairos M, Bech $\mathrm{M}$, Schaff $\mathrm{F}$, et al. Bone mineral crystal size and organization vary across mature rat bone cortex. J Struct Biol. 2016;195:337-44. https://doi.org/10.1016/j.jsb.2016.07.005

62. Georgiadis M, Guizar-Sicairos M, Zwahlen A, Trussel AJ, Bunk O, Muller R, et al. 3D scanning SAXS: a novel method for the assessment of bone ultrastructure orientation. Bone. 2015;71:42-52. https://doi.org/10.1016/j.bone.2014.10.002

63. Liebi M, Georgiadis M, Menzel A, Schneider P, Kohlbrecher J, Bunk $\mathrm{O}$, et al. Nanostructure surveys of macroscopic specimens by small-angle scattering tensor tomography. Nature. 2015;527:349-52. https://doi.org/10.1038/nature16056

64. Schaff F, Bech M, Zaslansky P, Jud C, Liebi M, Guizar-Sicairos $\mathrm{M}$, et al. Six-dimensional real and reciprocal space small-angle $\mathrm{X}$ ray scattering tomography. Nature. 2015;527:353-6. https://doi. org/10.1038/nature 16060

65. Grunewald TA, Ogier A, Akbarzadeh J, Meischel M, Peterlik H, Stanzl-Tschegg $\mathrm{S}$, et al. Reaction of bone nanostructure to a biodegrading Magnesium WZ21 implant-A scanning smallangle X-ray scattering time study. Acta Biomater. 2016;31:448-57. https://doi.org/10.1016/j.actbio.2015.11.049 
66. Grunewald TA, Rennhofer H, Hesse B, Burghammer M, StanzlTschegg SE, Cotte M, et al. Magnesium from bioresorbable implants: distribution and impact on the nano and mineral structure of bone. Biomaterials. 2016;76:250-60. https://doi.org/10. 1016/j.biomaterials.2015.10.054

67. Dierolf M, Menzel A, Thibault P, Schneider P, Kewish CM, Wepf $\mathrm{R}$, et al. Ptychographic X-ray computed tomography at the nanoscale. Nature. 2010;467:436-9. https://doi.org/10.1038/na ture09419

68. Sundell G, Dahlin C, Andersson M, Thuvander M. The boneimplant interface of dental implants in humans on the atomic scale. Acta Biomater. 2017;48:445-50. https://doi.org/10.1016/j. actbio.2016.11.044
69. Langelier B, Wang X, Grandfield K. Atomic scale chemical tomography of human bone. Sci Rep. 2017;7:39958 https://doi. org/10.1038/srep39958

70. Binkley DM, Grandfield K. Advances in multiscale characterization techniques of bone and biomaterials interfaces. Acs Biomater Sci Eng. 2017. https://doi.org/10.1021/acsbiomaterials.7b00420

71. Zimmermann EA, Schaible E, Gludovatz B, Schmidt FN, Riedel $\mathrm{C}$, Krause $\mathrm{M}$, et al. Intrinsic mechanical behavior of femoral cortical bone in young, osteoporotic and bisphosphonate-treated individuals in low- and high energy fracture conditions. Sci Rep. 2016;6:21072 https://doi.org/10.1038/srep21072 